\title{
FAKTOR- FAKTOR YANG BERHUBUNGAN DENGAN PEMILIHAN KONTRASEPSI SUNTIK DI BPM LISMARINI PALEMBANG
}

\author{
Lidya Fransisca \\ Akademi Kebidanan Al-Su'aibah Palembang \\ J1. Sukabangun II No. 1451 Rt.25/04 Km. 6,5 Palembang \\ Email : lie_fr@yahoo.com
}

\begin{abstract}
Abstrak
Indonesia merupakan sebuah negara berkembang dengan perkiraan penduduk pertengahan pada 2013 sebesar 248,8 juta jiwa dengan laju pertumbuhan penduduk sebesar 1,48\%. Sehingga untuk menekan jumlah penduduk tersebut maka digalakkan program keluarga berencana (KB).. Kontrasepsi hormonal merupakan jenis kontrasepsi yang paling disukai oleh para peserta keluarga berencana (KB) terutama $K B$ suntik.Penelitian ini bertujuan untuk mengetahui faktor-faktor yang berhubungan dengan pemilihan kontrasepsi suntik di BPM Lismarini Palembang. Jenis penelitian ini adalah survey analitik dengan pendekatan cross sectional. Populasi penelitian adalah semua akseptor KB hormonal di BPM Lismarini Palembang tahun 2017. Sampel penelitian menggunakan tehnik simpel random sampling sehingga didapatkan sampel berjumlah 212 responden. Uji statistik yang digunakan untuk menganalisis data pada penelitian ini adalah uji chi - square. Hasil penelitian didapatkan ada hubungan antara umur dengan pemilihan kontrasepsi suntik dengan $\rho$ value 0,003, tidak ada hubungan antara tingkat pendidikan dengan pemilihan kontrasepsi suntik dengan $\rho$ value 0.189 dan tidak ada hubungan antara pekerjaan dengan pemilihan kontrasepsi suntik dengan $\rho$ value 0,886di BPM Lismarini Palembang pada tahun 2017. Di harapkan pada peneliti selanjutnya agar dapat melakukan penelitian untuk mengetahui dan melanjutkan penelitian dengan variabel lain agar hasil penelitian yang didapat menjadi lebih akurat lagi.
\end{abstract}

Kata kunci : Umur, pendidikan, pekerjaan, kontrasepsi suntik

\begin{abstract}
Indonesia is a developing country with an estimated middle population in 2013 of 248.8 million with a population growth rate of $1.48 \%$. So as to reduce the population, family planning (KB) programs are encouraged. Hormonal contraception is the type of contraception that is most preferred by family planning participants, specially injection. This study aims to determine the factors of correlation with the selection of injection contraception at BPM Lismarini Palembang. This type of research is an analytical survey with a cross sectional approach. The study population was all hormonal family planning acceptors at BPM Lismarini Palembang in 2017. The study sample used a simple random sampling technique so that the sample was 212 respondents. The statistical test used to analyze the data in this study was the chi-square test. The results showed that there was a correlation between age and injection contraceptive selection with $\rho$ value 0.04, there was no correlation between education and injection contraceptive selection with $\rho$ value 0,189 and there was no correlation between occupation and injection contraceptive selection education with $\rho$ value 0.886 at BPM Lismarini Palembang in 2017. Future researchers are expected to be able to conduct research to find out and continue research with other variables so that the results of the research obtained will be more accurate.
\end{abstract}

Keywords : Age, education, occupation, injection contraception 


\section{PENDAHULUAN}

Tingginya angka kelahiran di Indonesia saat ini merupakan salah satu masalah yang besar dan memerlukan perhatian khusus dalam penanganannya untuk pengendalian angka kelahiran tersebut. Salah satu bentuk perhatian khusus pemerintah dalam menanggulangi hal tesebut adalah dengan melaksanakan pembangunan dan keluarga berencana $(\mathrm{KB})$ secara komprehensif. Program Keluarga Berencana memiliki makna yang sangat strategis, komprehensif dan fundamental dalam mewujudkan manusia Indonesia yang sehat dan sejahtera. (Huda, dkk, 2016).

Dalam Islam KB termasuk ke dalam aghayyuru al-ahkaami bitaghayyuri alazminati wa-al-amkinati wa al-ahwaali (hukum - hukum yang bisa berubah sesuai dengan perubahan zaman, tempat dan keadaan). Firman Allah dalam Surat AnNisa ayat 9 menyebutkan bahwa "Dan hendaklah takut kepada Allah orang - orang yang seandainya meninggalkan di belakang mereka anak - anak yang lemah, yang mereka khawatir terhadap (kesejahteraan) mereka. Oleh sebab itu, hendaklah mereka bertakwa kepada Allah dan hendaklah mereka mengucapkan perkataan yang benar “. Dalam ayat tersebut, orang tua diperintahkan untuk melahirkan dan mendidik anak dengan baik sehingga menciptakan generasi yang berkualitas dalam mimpin bangsa (Nurmila, 2011).

Indonesia merupakan sebuah negara berkembang dengan perkiraan penduduk pertengahan pada 2013 sebesar 248,8 juta jiwa dengan laju pertumbuhan penduduk sebesar 1,48\%. Laju pertumbuhan ditentukan oleh kelahiran dan kematian dengan adanya perbaikan pelayanan kesehatan menyebabkan tingkat kematian rendah, sedangkan tingkat kelahiran tetap tinggi hal ini penyebab utama ledakan penduduk. Sehingga untuk menekan jumlah penduduk tersebut maka digalakkan program KB (BPS, 2013).
Program Keluarga Berencana (KB) dilakukan dalam rangka mengatur jumlah kelahiran atau menjarangkan kelahiran. Sasaran program KB adalah Pasangan Usia Subur (PUS) yang lebih dititikberatkan pada kelompok Wanita Usia Subur (WUS) yang berada pada kisaran usia 15-49 tahun (Kurniawan dkk, 2017).

Kontrasepsi hormonal merupakan jenis kontrasepsi yang paling disukai oleh para peserta keluarga berencana (KB) terutama KB suntik. Cakupan peserta KB Aktif di Indonesia pada tahun 2017 dengan jumlah Pasangan Usia Subur (PUS) sebanyak 37.338.268 akseptor dan peserta KB aktif sebesar 23.606.218 akseptor, meliputi suntik sebanyak 14.817.663 akseptor $(62,77 \%)$, pil sebanyak 4.069 .844 akseptor (17,24\%), IUD (Intra Uterine Device) sebanyak 1.688 .685 akseptor (7,15\%), implan sebanyak 1.650.227 akseptor $(6,99 \%)$, Metode Operasi Wanita (MOW) sebanyak 655.762 akseptor (2,78\%), kondom sebanyak 288.388 akseptor $(1,22 \%)$ dan Metode Operasi Pria (MOP) sebanyak 124.262 akseptor $(0,53 \%)$ (Kurniawan dkk, 2017). Dilihat dari data di atas sebagian besar para pasangan usia subur di Indonesia menggunakan alat kontrasepsi hormonal terutama suntik dan pil.

Kontrasepsi KB suntik ini banyak dipilih karena merupakan alternatif kontrasepsi yang sangat baik bagi wanita yang menginginkan kontrasepsi jangka panjang yang sangat efektif. Selain itu karena kontrasepsi ini juga tidak mempengaruhi proses menyusui terutama $\mathrm{KB}$ suntik 3 bulan, tidak bergantung pada faktor senggama, bisa digunakan oleh semua wanita usia produktif, praktis dan mudah karena mereka hanya perlu melakukannya 1 - 3 bulan sekali serta murah (Saifuddin, 2012).

Menurut Handayani dalam Septianingrum (2017) ada beberapa faktor yang mempengaruhi seseorang dalam memilih alat kontrasepsi diantaranya usia, tingkat pendidikan, pekerjaan, pengetahuan, 
ekonomi, tarif pelayanan, persetujuan pasangan dan budaya.

Di kota Palembang, pada tahun 2015jumlah peserta KB aktif adalah 217.117 akseptor meliputi suntik sebanyak 75.727 akseptor, pil sebanyak 52.722 akseptor, implant sebanyak 32.438 akseptor, kondom sebanyak 16.937 akseptor, IUD sebanyak 22.478 akseptor, MOW sebanyak 15.892 akseptor dan MOP sebanyak 923 akseptor (BPS Prov. SumSel, 2015).

Sedangkan di BPM Lismarini Palembang pada tahun 2017 jumlah peserta KB sebanyak 593 akseptor yang meliputi pil 193 akseptor, suntik 188 akseptor, kondom 92 akseptor, implant 68 akseptor dan IUD 52 akseptor. Dilihat dari dari data tersebut peserta KB suntik di BPM Lismarini menduduki peringkat kedua setelah pil.

Penelitian ini bertujuan untuk mengetahui hubungan antar umur, tingkat pendidikan dan pekerjaan ibu dengan pemilhan kontrasepsi suntik di BPM Lismarini Palembang tahun 2017.

\section{METODE PENELITIAN}

\section{Jenis Penelitian}

Jenis penelitian ini menggunakan metode survey analitik dengan pendekatan cross sectional.

\section{Waktu dan Penelitian}

Lokasi penelitian dilakukan di BPM Lismarini Palembang pada bulan Juni sampai Agustus 2018.

\section{Target / Subjek Penelitian}

Populasi pada penelitian ini adalah semua ibu KB hormonal di BPM Lismarini tahun 2017, dengan jumlah sampel sebanyak 212 orang. Tehnik pengambilan sampel dilakukan dengan sampel random sampling.

\section{Prosedur}

Penelitian ini dilakukan setelah mendapat persetujuan dari pihak BPM Lismarini untuk mengambil data yang dibutuhkan yaitu data dari rekam medic pelayanan KB di BPM Lismarini Palembang.

\section{Data, Instrumen dan Teknik Pengumpulan Data}

Data yang digunakan pada penelitian ini adalah data sekunder yang didapatkan dari catatan rekam medic pelayanan KB dengan menggunakan instrument checklist yang telah disusun oleh peneliti sesuai dengan kebutuhan penelitian.

Teknik Analisa Data

Data yang didapat kemudian diolah dan dilakukan analisa data univariat dan bivariat. Dimana analisa univariat untuk mendiskripsikan atau menggambarkan distribusi masing - masing variable yaitu variable terikat dan variable bebas dan analisa bivariat untuk melihat hubungan terhadap dua variabel yang diduga berhubungan atau berkorelasi dengan menggunakan uji chi-square.

\section{HASIL PENELITIAN DAN PEMBAHASAN}

A. Analisa univariat

\section{Pemilihan kontrasepsi suntik}

Distribusi frekuensi pemilihan kontrasepsi suntik dalam penelitian ini dapat dilihat pada tabel 1

\section{Tabel 1}

Distribusi frekuensi pemilihan kontrasepsi suntik

\begin{tabular}{lccc}
\hline $\begin{array}{l}\mathbf{N} \\
\mathbf{0}\end{array}$ & $\begin{array}{l}\text { Kontrasepsi } \\
\text { suntik }\end{array}$ & $\begin{array}{l}\text { Freku } \\
\text { ensi } \\
(\mathbf{n})\end{array}$ & $\begin{array}{l}\text { Persen } \\
\text { tase } \\
(\boldsymbol{\%})\end{array}$ \\
\hline $\mathbf{1}$ & Ya & 103 & 48,6 \\
$\mathbf{2}$ & Tidak & 109 & 51,4 \\
\hline & Jumlah & 212 & 100 \\
\hline
\end{tabular}

Berdasarkan tabel 1 diketahui bahwa dari 212 responden, ibu yang kontrasepsi suntik berjumlah 103 $(48,6 \%)$, lebih sedikit dibandingkan ibu yang tidak kontrasepsi suntik yang berjumlah $109(51,4 \%)$.

\section{Umur Responden}

Distribusi frekuensi umur responden dalam penelitian ini dapat dilihat pada tabel 2. 
Tabel 2

Distribusi frekuensi umur responden

\begin{tabular}{cccc}
\hline $\mathbf{N}$ & $\begin{array}{l}\text { Umur } \\
\text { respond } \\
\text { en }\end{array}$ & $\begin{array}{l}\text { Frekue } \\
\text { nsi (n) }\end{array}$ & $\begin{array}{l}\text { Persenta } \\
\text { se (\%) }\end{array}$ \\
\hline $\mathbf{1}$ & $\begin{array}{c}\text { Tidak } \\
\text { berisiko }\end{array}$ & 163 & 76,9 \\
$\mathbf{2}$ & $\begin{array}{c}\text { Berisiko } \\
\text { Jumlah }\end{array}$ & 49 & 23,1 \\
\hline
\end{tabular}

Berdasarkan tabel.2 diketahui bahwa dari 212 responden, umur responden yang tidak berisiko berjumlah 163 (76,9\%), lebih banyak dibandingkan umur responden yang berisiko yang berjumlah $49(23,1 \%)$.

\section{Tingkat pendidikan responden}

Distribusi frekuensi tingkat pendidikan responden dalam penelitian ini dapat dilihat pada tabel 3

Tabel 3

Distribusi frekuensi tingkat pendidikan responden

\begin{tabular}{cccc}
\hline No & $\begin{array}{l}\text { Pendidikan } \\
\text { responden }\end{array}$ & $\begin{array}{l}\text { Frekuensi } \\
\text { (n) }\end{array}$ & $\begin{array}{l}\text { Perse } \\
\text { ntase } \\
(\boldsymbol{\%})\end{array}$ \\
\hline $\mathbf{1}$ & Tinggi & 168 & 79,2 \\
$\mathbf{2}$ & Rendah & 44 & 20,8 \\
\hline & Jumlah & 212 & 100 \\
\hline
\end{tabular}

Berdasarkan tabel 3 diketahui bahwa dari 212 responden, responden yang berpendidikan tinggi berjumlah 168 (79,2\%), lebih banyak dibandingkan responden yang berpendidikan rendah yang berjumlah 44 (20,8\%).

\section{Pekerjaan responden}

Distribusi frekuensi pekerjaan responden dalam penelitian ini dapat dilihat pada tabel 4
Tabel 4

Distribusi frekuensi pekerjaan responden

\begin{tabular}{|c|c|c|c|}
\hline $\begin{array}{l}\mathbf{N} \\
\mathbf{0}\end{array}$ & $\begin{array}{l}\text { Pekerja } \\
\text { an } \\
\text { respond } \\
\text { en }\end{array}$ & $\begin{array}{l}\text { Frekue } \\
\text { nsi (n) }\end{array}$ & $\begin{array}{l}\text { Persenta } \\
\text { se }(\%)\end{array}$ \\
\hline 1 & Bekerja & 70 & 33 \\
\hline 2 & $\begin{array}{c}\text { Tidak } \\
\text { bekerja }\end{array}$ & 142 & 67 \\
\hline & Jumlah & 212 & 100 \\
\hline
\end{tabular}

Berdasarkan tabel 4 diketahui bahwa dari 212 responden, responden yang bekerja berjumlah $70(33 \%)$, lebih sedikit dibandingkan responden yang tidak bekerja yang berjumlah 142 (67\%).

\section{B. Analisa bivariat}

\section{Hubungan antara umur responden dengan pemilihan kontrasepsi suntik}

Hasil analisis hubungan antara umur responden dengan pemilihan kontrasepsi suntik, dapat dilihat pada tabel. 5

Tabel 5

Hubungan antara umur responden dengan pemilihan kontrasepsi suntik

\begin{tabular}{|c|c|c|c|c|c|c|c|}
\hline \multirow{3}{*}{ Umur } & \multicolumn{4}{|c|}{$\begin{array}{c}\text { Pemilihan kontrasepsi } \\
\text { suntik }\end{array}$} & \multicolumn{2}{|c|}{ Total } & \multirow{3}{*}{$\begin{array}{c}\rho \\
\text { val } \\
\text { ue }\end{array}$} \\
\hline & \multicolumn{2}{|c|}{$\mathrm{Ya}$} & \multicolumn{2}{|c|}{ Tidak } & \multirow[b]{2}{*}{$\mathrm{N}$} & \multirow[b]{2}{*}{$\%$} & \\
\hline & $\mathrm{n}$ & $\%$ & $\mathrm{n}$ & $\%$ & & & \\
\hline $\begin{array}{l}\text { Tidak } \\
\text { berisiko }\end{array}$ & 86 & 52,8 & 77 & 47,2 & 163 & 100 & \multirow{2}{*}{$\begin{array}{l}0,0 \\
40\end{array}$} \\
\hline Berisiko & 17 & 34,7 & 32 & 65,3 & 49 & 100 & \\
\hline Jumlah & 103 & 48,6 & $\begin{array}{c}19 \\
9\end{array}$ & 51,4 & 212 & 100 & \\
\hline
\end{tabular}

Berdasarkan tabel 5 didapatkan bahwa dari 163 responden umur tidak berisiko yang memilih kontrasepsi suntik berjumlah 86 $(52,8 \%)$, sedangkan dari 49 responden umur berisiko yang 
memilih KB suntik berjumlah 17 $(34,7 \%)$. Dari hasil perhitungan uji chi - square diperoleh $\rho$ value 0,040 $\leq \alpha 0,05$, yang berarti bahwa ada hubungan antara umur responden dengan pemilihan kontrasepsi suntik.

Hal ini sesuai dengan penelitian Grestasari (2014) yang menyatakan bahwa ada hubungan antara usia dengan pemilihan jenis kontrasepsi di Desa Jetak Kecamatan Sidoharjo Kabupaten Sragen, dimana semakin tinggi umur seseorang maka tingkat kematangan dan kekeuatan seseorang akan lebih matang dalam berfikir.

Selain itu pemilihan kontrasepsi suntik oleh wanita usia subur (umur 20 - 34 tahun) karena suntik merupakan alat kontrasepsi yang praktis, aman, sederhana, murah dan tidak perlu takut lupa serta tidak mempengaruhi ASI. Selain itu kontrasepsi suntik memiliki efektifitas yang tinggi bila penyuntikkan dilakukan secara terartur sesuai dengan jadwal yang telah ditentukan (Darmawati, 2012)

\section{Hubungan antara tingkat pendidikan responden dengan pemilihan kontrasepsi suntik}

Hasil analisis hubungan antara tingkat pendidikan responden dengan pemilihan kontrasepsi suntik, dapat dilihat pada tabel 6

Tabel. 6

Hubungan antara tingkat pendidikan responden dengan pemilihan kontrasepsi suntik

\begin{tabular}{|c|c|c|c|c|c|c|c|}
\hline \multirow{4}{*}{$\begin{array}{c}\text { Tingkat } \\
\text { pendidi } \\
\text { kan }\end{array}$} & \multirow{2}{*}{\multicolumn{4}{|c|}{$\begin{array}{c}\text { Pemilihan kontrasepsi } \\
\text { suntik }\end{array}$}} & \multirow{2}{*}{\multicolumn{2}{|c|}{ Total }} & \multirow{4}{*}{$\begin{array}{c}\rho \\
\text { valu } \\
\mathbf{e}\end{array}$} \\
\hline & & & & & & & \\
\hline & \multicolumn{2}{|c|}{$\mathrm{Ya}$} & \multicolumn{2}{|c|}{ Tidak } & \multirow[b]{2}{*}{$\mathrm{N}$} & \multirow[b]{2}{*}{$\%$} & \\
\hline & $\mathrm{n}$ & $\%$ & $\mathrm{n}$ & $\%$ & & & \\
\hline Tinggi & 86 & 51,2 & 82 & 48,8 & 168 & 100 & \multirow{2}{*}{$\begin{array}{c}0,18 \\
9\end{array}$} \\
\hline Rendah & 17 & 38,6 & 27 & 61,4 & 44 & 100 & \\
\hline Jumlah & 103 & 48,6 & 109 & 51,4 & 212 & 100 & \\
\hline
\end{tabular}

Berdasarkan table 6 didapatkan bahwa dari 168 responden yang berpendidikan tinggi yang memilih kontrasepsi suntik berjumlah 86 $(51,2 \%)$, sedangkan dari 44 responden yang berpendidikan rendah yang memilih $\mathrm{KB}$ suntik berjumlah 17 (38,6\%). Dari hasil perhitungan uji chi - square diperoleh $\rho$ value $0,189>\alpha 0,05$, yang berarti bahwa tidak ada hubungan antara tingkat pendidikan responden dengan pemilihan kontrasepsi suntik.

Hal ini sesuai dengan penelitian Irmawati (2012) yang hormonal. Hal ini dikarenakan dalam menggunakan alat kontrasepsi hormonal akseptor KB tidak mesti menempuh jalur pendidikan formal menyatakan bahwa tidak ada pengaruh pendidikan terhadap penggunaan kontrasepsi karena mereka sering mendapatkan informasi mengenai alat kontrasepsi hormonal baik oleh petugas kesehatan setempat, dari media elektronik maupun dari sesame rekan.

Menurut Budiman dan Riyanto (2013) pendidikan formal sangat besar pengaruhnya terhadap pengetahuan seseorang, bila seseorang berpendidikan tinggi maka akan memiliki pengetahuan yang tinggi pula sebaliknya jika seseorang memiliki pendidikan rendah akan memiliki pengetahuan yang rendah dan akan mempengaruhi dalam memahami sesuatu hal. Akan tetapi perlu ditekankan bahwa seseorang yang berpendidikan rendah tidak mutlak berpengetahuan rendah pula dinama pengetahuan ataupun informasi dapat diperoleh bukan hanya secara formal tetapi juga non formal. 


\section{Hubungan antara pekerjaan responden dengan pemilihan kontrasepsi suntik}

Hasil analisis hubungan antara pekerjaan responden dengan pemilihan kontrasepsi suntik, dapat dilihat pada tabel 7

Tabel 7

Hubungan antara pekerjaan responden dengan pemilihan kontrasepsi suntik

\begin{tabular}{|c|c|c|c|c|c|c|c|}
\hline \multirow{3}{*}{$\begin{array}{c}\text { Pekerj } \\
\text { aan }\end{array}$} & \multicolumn{4}{|c|}{$\begin{array}{c}\text { Pemilihan kontrasepsi } \\
\text { suntik }\end{array}$} & \multicolumn{2}{|c|}{ Total } & \multirow{3}{*}{$\begin{array}{c}\rho \\
\text { valu } \\
\mathrm{e}\end{array}$} \\
\hline & \multicolumn{2}{|c|}{$\mathrm{Ya}$} & \multicolumn{2}{|c|}{ Tidak } & \multirow[b]{2}{*}{$\mathrm{N}$} & \multirow[b]{2}{*}{$\%$} & \\
\hline & $\mathrm{n}$ & $\%$ & $\mathrm{n}$ & $\%$ & & & \\
\hline Bekerja & 35 & 50 & 35 & 50 & 70 & 100 & \multirow[b]{2}{*}{$\begin{array}{c}0,88 \\
6\end{array}$} \\
\hline $\begin{array}{l}\text { Tidak } \\
\text { bekerja }\end{array}$ & 68 & 47,9 & 74 & 52,1 & 142 & 100 & \\
\hline$\underset{\mathbf{h}}{\mathrm{Jumla}}$ & 103 & 48,6 & $\begin{array}{c}10 \\
9\end{array}$ & 51,4 & 212 & 100 & \\
\hline
\end{tabular}

Berdasarkan tabel 7 didapatkan bahwa dari 70 responden yang bekerja yang memilih kontrasepsi suntik berjumlah $35 \quad(50 \%)$, sedangkan dari 142 responden yang tidak bekerja yang memilih KB suntik berjumlah 68 (47,9\%). Dari hasil perhitungan uji chi - square diperoleh $\rho$ value $0,886>\alpha 0,05$, yang berartibahwatidakadahubung anantara pekerjaan responden dengan pemilihan kontrasepsi suntik.

Hal ini sesuai dengan penelitian Irmawati (2012) yang menyatakan bahwa tidak ada pengaruh pekerjaan terhadap penggunaan kontrasepsi hormonal. Wanita bekerja diduga mempunyai kecenderungan lebih tinggi untuk memakai alat kontrasepsi. Nilai waktu yang dimiliki wanita bekerja adalah lebih mahal dibandingkan dengan wanita yang tidak bekerja. Kesempatan wanita bekerja untuk mengurus anak lebih sedikit diandingkan dengan yang tidak bekerja. Oleh karena itu wanita bekerja akan cenderung memakai alat kontrasepsi untuk membatasi jumlah anak yang bersifat permanen. Sehingga wanita bekerja lebih sedikit yang memilih kontrasepsi suntik, mereka lebih banyak yang memilih alat kontrasepsi seperti AKDR. Hal ini dikarenakan menurut pertimbangan mereka lebih menghemat waktu.

\section{SIMPULAN}

1. Ada hubungan antara umur responden dengan pemilihan kontrasepsi suntik dengan $\rho$ value 0,040 .

2. Tidak ada hubungan antara tingkat pendidikan responden dengan pemilihan kontrasepsi suntik dengan $\rho$ value 0,189 .

3. Tidak ada hubungan antara pekerjaan responden dengan pemilihan kontrasepsi suntik dengan $\rho$ value 0,886 .

\section{SARAN}

Di harapkan pada peneliti selanjutnya agar dapat melakukan penelitian untuk mengetahui dan melanjutkan penelitian dengan variabel lain agar hasil penelitian yang didapat menjadi lebih akurat lagi.

\section{UCAPAN TERIMA KASIH}

Peneliti mengucapkan terimakasih kepada pihak BPM Lismarini Palembang yang telah banyak membantu dalam pelaksaan penelitian ini.

\section{DAFTAR PUSTAKA}

BPS Prov. Sumatera Selatan. Jumlah Peserta KB Aktif Menurut Kabupaten / Kota di Provinsi Sumatera Selatan 2015.

https://sumsel.bps.go.id/dynamictable/ 2016/10/31/202/jumlah-peserta-kbaktif-menurut-kabupaten-kota-diprovinsi-sumatera-selatan-2015.html. diakses tanggal 23 Mei 2018. 
Budiman dan Riyanto, A. 2013. Kapita Selekta Kuesioner. Salemba Medika; Jakarta.

Darmawati, 2012. Faktor - Faktor Yang Mempengaruhi Wanita Usia Subur Memilih Kontrasepsi Suntik. Idea Nursing Journal Vol. II. No.3: Idea Nursing Journal Publisher; Fakultas Keperawatan - Universitas Syiah Kuala.

Grestasari, Luluk Erdika. 2014. Hubungan Antara Tingkat Pendidikan, Pengetahuan Dan Usia Ibu PUS Dengan Pemilihan Jenis Kontrasepsi Di Desa Jetak Kecamatan Sidoharjo Kabupaten Sragen. Naskah Publikasi Universitas Muhammadiyah Fakultas Ilmu Kesehatan. Surakarta.

Huda, Andari Nurul dkk. 2016. Faktor Faktor Yang Berhubungan Dengan Perilaku Penggunaan Alat Kontrasepsi Pada Wanita Usia Subur Di Puskesmas Jombang Kota Tangerang Selatan. Jurnal Kesehatan Masyarakat (e-Journal) Volume 4, Nomor 1, Januari 2016 hal 461 469.http://ejournalsl.undip.ac.id/index.php./jkm

Irmawati. 2012. Faktor - Faktor Yang Mempengaruhi Penggunaan Alat Kontrasepsi Hormonal Pada Akseptor
KB Di Puskesmas Samata Kel. Romang Polong Kec. Sombo Opu Kabupaten Gowa 2012. Makassar; Universitas Islam Negeri Alauddin Fakultas Ilmu Kesehatan Jurusan Keperawatan.

Kurniawan, dkk.2017. Profil Kesehatan Indonesia Tahun 2016.Kemenkes RI; Jakarta.

Nurmila, Nina. 2011. Tafsir Edisi 36 : Keluarga Berencana dan Pemberdayaan Perempuan. Rahima (Pusat Pendidikan dan Informasi Islam dan Hak - Hak Perempuan.). http://rahima.or.id/index.php?option=c om_content\&view=article\&id=827:taf sir-alquran-keluarga-berencana-danpemberdayaan-

perempuan \&catid $=35:$ tafsirtafsiralqura $\underline{\text { n\&Itemid }=306}$ diakses pada tanggal 22 Mei 2018.

Saifuddin, Abdul Bari. 2012. Buku Panduan Praktis Pelayanan Kontrasepsi. PT. Bina Pustaka Sarwono Prawirohardjo; Jakarta.

Septianingrum, dkk. 2017. Faktor-Faktor Yang Mempengaruhi Tingginya Akseptor KB Suntik 3 Bulan. Jurnal Ners dan Kebidanan, Volume 5, No.1, April 2018 hal. 15 - 19. 